\title{
A Study on Design Techniques for Creating Expectation Image in Different Product-using Stage
}

\author{
Yung-chin TSAO*, Pochuan CHEN* and Yen-pang YANG** \\ * Graduate Institute of Design Science, Tatung University. No. 40, Sec. 3, Zhongshan N. Rd., Taipei City 104, Taiwan (R.O.C.) \\ ** Kuzai Art Design Ltd. No. 62, Lane 208, Wen de Rd., Taipei City, Taiwan (R.O.C.)
}

\begin{abstract}
The research is a study on design techniques for creating "Expectation" image in product using process. In order to have a better understanding, the product using process was divided in 3 stages: Starting, Development, and Ending. 18 samples were created based on the design technique combinations from previous work. And the samples were tested via Semantic Differential Scale, to investigate the emotional feedback regarding to the expectation image. The testing result was further categorized into 6 groups by a Cluster Analysis. The expected image for using products consists of 3 aspects: "agitated -- calm" aspect for showing the emotional change levels, "ambiguous -- transparent" aspect for delivering the users definite messages and "sequential -- accidental" aspect for predicting the next step. Testing result also shows that samples with associated appearance, simple operation and clear result has the highest scores in "Expecting" (5.35), "Interesting" (5.41), and "Favorable" (5.20) evaluation.
\end{abstract}

Keywords: design technique, Product use process, expected image, Behavior unitization

\section{INTRODUCTION}

Emotion and affect factors have become more and more important in product design field. Norman [1] has studied how these factors worked and proposed a three level model: visceral, behavioral, and reflective level. In general, positive emotion will make people have more willing to use or own a product.

Expectation refers to a personal thought which led by a hope, and the result will cause people toward a positive and aggressive direction. [2] In other words, when someone had the so-called expecting feeling to something, it will make people feel even more eager about the thing he expected. If expecting image can be generated during people using products, it will raise the percentage that people like the product. For this reason, this study is aimed to explore the design techniques to create expecting image during product-use.

In terms of the definition of product-use stage, Edward Reed [3] has proposed a method for dividing people's everyday actions into units, and found the everyday actions can be described as a hierarchical organization. Tsao and Hsiung [4] explored the relationship between the adverbial images of complex actions in using utensils and the forms of the utensils. It is found that the behavior of use is organized by a series of single actions. And different process of use may result in different image. It is important that how to divide a behavior into units, Chou [5] has suggested 3 stages for describing a story: starting, development, and ending. In this study, the 3 stages were applied to divide the product-use process.

This study is a continuing research. In previous work, Tsao et al. [6] have found that the starting stage of expected image was constructed by two sub-concepts: "attractive incentives" and "expectation on the results". The development stage of expected image was constructed by three sub-concepts: "cautious", "impatient" and "excited". The ending stage of expected image was constructed by three sub-concepts: "different from the expected", "going to be revealed" and "meet the expectation". As shown in Table 1.

Tsao et al. also suggested the corresponding design techniques for each sub-concept of expected image. There were total 18 design combinations, as shown in Figure 1.

This research aims to further explore the corresponding relationships for design techniques and expectation image. For this purpose, 18 product samples were created according to the 18 design technique combinations.

\section{EXPERIMENT DESIGN}

\subsection{Testing samples}

The 18 product samples were created to be 3D models by using Autodesk 3D Max. And the product-use process 
Table 1: Expected image construct.

\begin{tabular}{|c|c|c|}
\hline Stages & Sub-concept & Descriptions \\
\hline \multirow{2}{*}{$\begin{array}{l}\text { Starting stage of } \\
\text { expected image }\end{array}$} & G1: Attractive incentives & $\begin{array}{l}\text { Be tempted by fresh or charming things which } \\
\text { make people unconsciously to follow. }\end{array}$ \\
\hline & G2: Expectation on the results & $\begin{array}{l}\text { There is a specific goal for accomplishment } \\
\text { and look forward to the result. }\end{array}$ \\
\hline \multirow{3}{*}{$\begin{array}{l}\text { Development stage of } \\
\text { expected image }\end{array}$} & G1: Cautious & $\begin{array}{l}\text { A careful and discreet process with an uneasy } \\
\text { mind. }\end{array}$ \\
\hline & G2: Impatient & Being eager and can't wait to know the result. \\
\hline & G3: Excited & A state in high spirits. \\
\hline \multirow{3}{*}{$\begin{array}{l}\text { Ending stage of } \\
\text { expected image }\end{array}$} & G1: Different from the expected & $\begin{array}{l}\text { Discovering a different result from the } \\
\text { expectation, and lead to disappointment. }\end{array}$ \\
\hline & G2: Going to be revealed & $\begin{array}{l}\text { The almost certain state before the result is } \\
\text { exhibited. (in a viewpoint of emotion level) }\end{array}$ \\
\hline & G3: Meet the expectation & $\begin{array}{l}\text { The result is as expected and make people } \\
\text { feel satisfied and delighted. }\end{array}$ \\
\hline
\end{tabular}

was simulated by Macromedia Flash MX. Table 2 shows one testing sample. The sample was created from the combination of "the appearance is different from the existing features", "back and forth operation method" and "presenting the unforeseen result". At starting stage, a dog-shape product was seen, but people couldn't predict the purpose and functions of the product. At development stage, the dog stepped forward and the body was gradually strengthening by continuous touching the head and mouth. At ending stage, when the dog's body reached the longest length, a clock was displayed on the dog's body. Since there wasn't any clue to make people connect a dog-shape and the touching operation to a clock, this will bring an unforeseen result.

\subsection{Evaluation Adjective Pairs}

The adjective pairs of the expected image used in this experiment were suggested by Chen and Tsao [7], which were 10 adjective pairs to describe the expected image in
Table 2: Testing sample example.

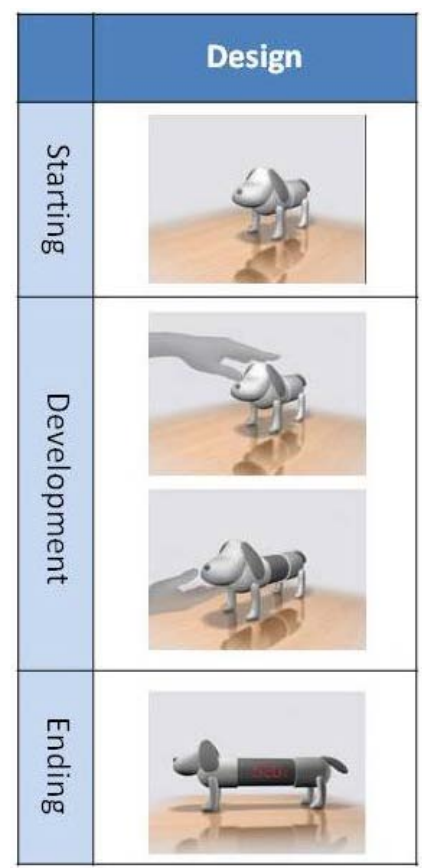

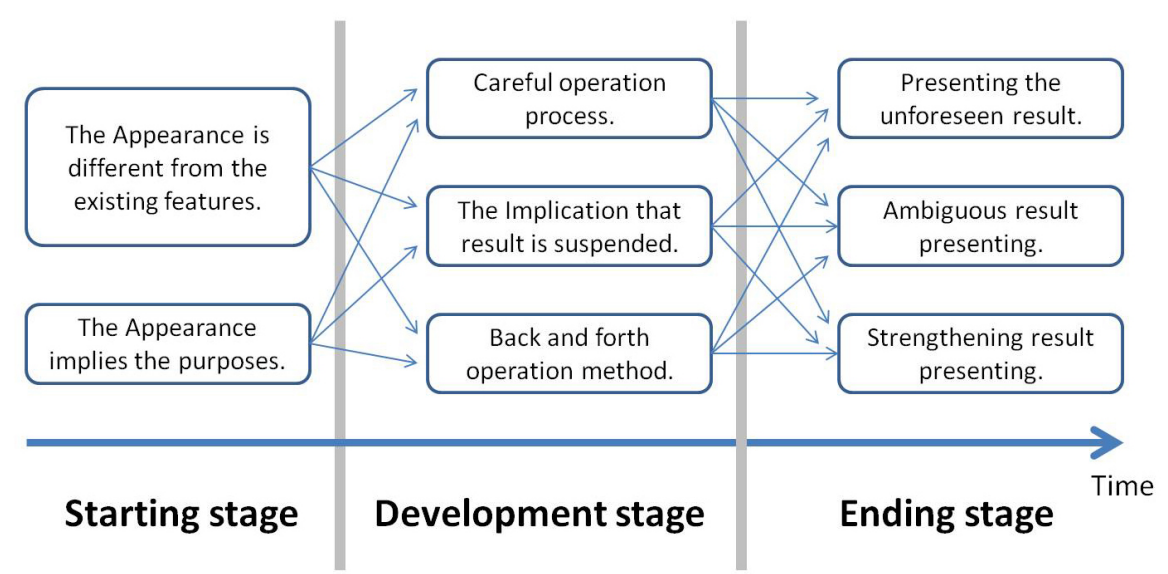

Figure 1: 18 design technique combinations. 
the process of using product, as shown in Table 3.

Besides, in order to understand not only the overall expecting level, but also if people like or feel interesting about the use process and result, 3 additional pairs were added, which were "expecting -- random", "interesting -boring" and "favorable -- disliked", as shown in Table 4.

\subsection{Subject}

30 subjects aged from 20 to 30 were participated in the experiment. Among them, 12 were males, and 18 were females.

\subsection{Experiment Method}

A Semantic Differential Scale was implemented in the experiment. There were 7 degrees on the scale, as shown in Figure 2. The subjects were asked to operate the Flash player to watch the product-use animation. And then answered the questionnaire. The samples were tested in same order by all subjects. When subjects played the flash animation, the product appearance was shown at the beginning, and subjects were asked to fill the starting stage questionnaire. Then subjects were asked to push the "play" button to play the animation. Till the animation stopped, subjects were asked to fill development stage

Table 3: 10 adjective pairs of the expected image in the process of using product.

\begin{tabular}{|c|c|}
\hline 1 & Expecting --disappointed \\
\hline 2 & Surprising --ordinary \\
\hline 3 & Eager --resistant \\
\hline 4 & Creative --old-fashioned \\
\hline 5 & Unknown --known \\
6 & Exciting --dull \\
\hline 7 & Changeable --fixed \\
\hline 8 & Sequential --accidental \\
\hline 9 & Clear --ambiguous \\
\hline 10 & Passionate --indifferent \\
\hline
\end{tabular}

Table 4: Overall evaluation pairs.

\begin{tabular}{|l|c|}
\hline 11 & Expecting -- random \\
\hline 12 & Interesting --boring \\
\hline 13 & Favorable --disliked \\
\hline
\end{tabular}

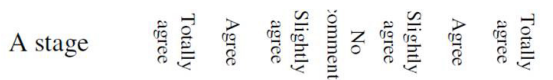

\begin{tabular}{|l|l|l|l|l|}
\hline 1 & Expecting & $\square \quad \square \square \square \square \square \square$ & Disappointed \\
\hline
\end{tabular}

Figure 2: Semantic Differential Scale. questionnaire. Then subjects were asked to push the "play" button again to continue playing the animation. When the animation stopped, subjects were asked to fill the ending stage questionnaire.

\section{RESULTS AND ANALYSIS}

In order to have a better understanding on the image construct, a Principle Component Analysis was used on the testing result data. There were 3 principle components be found from the data, the first principle component was constructed by "surprising -- ordinary", "exciting -- dull", and "expecting -- disappointed". Which represents the emotional changing level during product using process. And it can be treated as an "Agitated -- Calm" factor. The second principle component was constructed by "clear -ambiguous" and "unknown -- known". It represents the clearness level of messages delivered to the users in product use process. And it can be treated as a "ambiguous -- transparent" factor. The third principle component was "sequential -- accidental", which implies the level of predication toward the next step in product use process.

\subsection{Cluster Analysis}

A Cluster Analysis was used to further categorized the testing result. There were 6 groups be found from the Cluster Analysis, as shown in Figure 3. In order to better understand the overall image of each group, the 6 groups were plotted on the 2D image map which based on principle components as X, Y axis, as shown in Figure 4 and 5.

G1 group includes sample 9, 14, 18, and the overall tendency was "calm, transparent, and sequential". The feature of this group could be explained as "familiar appearance, constant operation, and rational result". G2

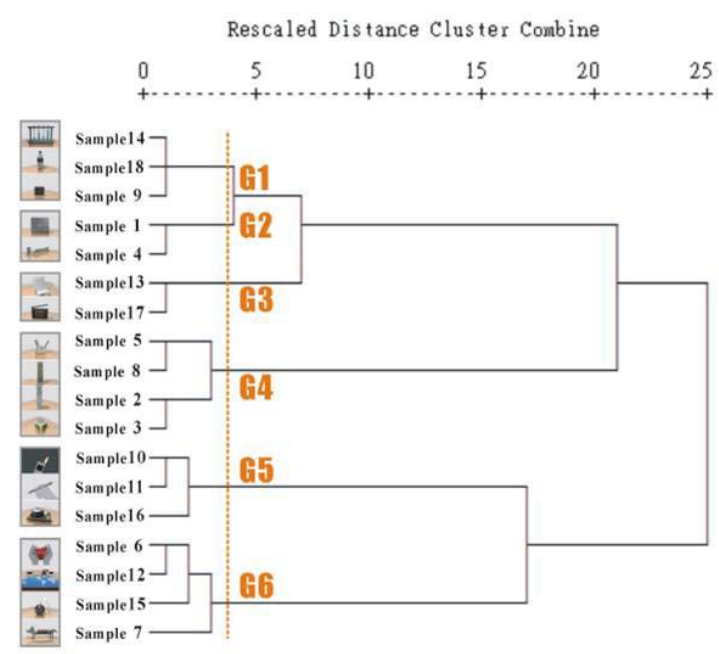

Figure 3: 6 groups from the cluster analysis. 


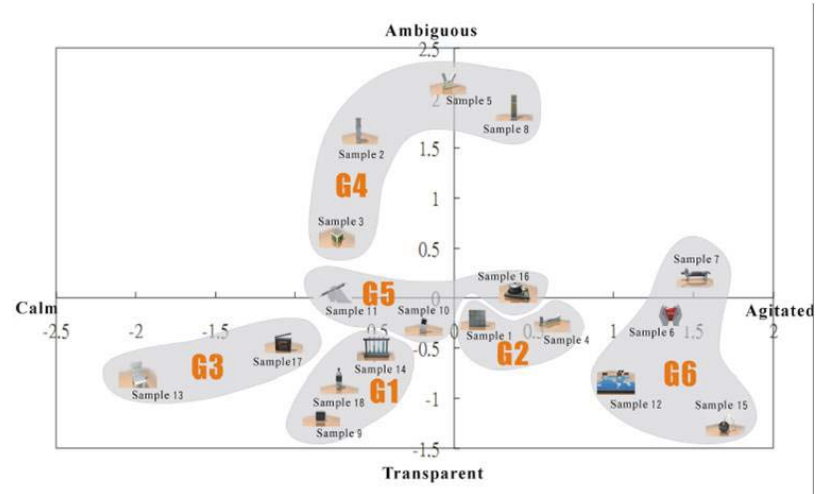

Figure 4: Image map plotted by using the first ( $\mathrm{X}$ axis) and the second ( $\mathrm{Y}$ axis) principle component.

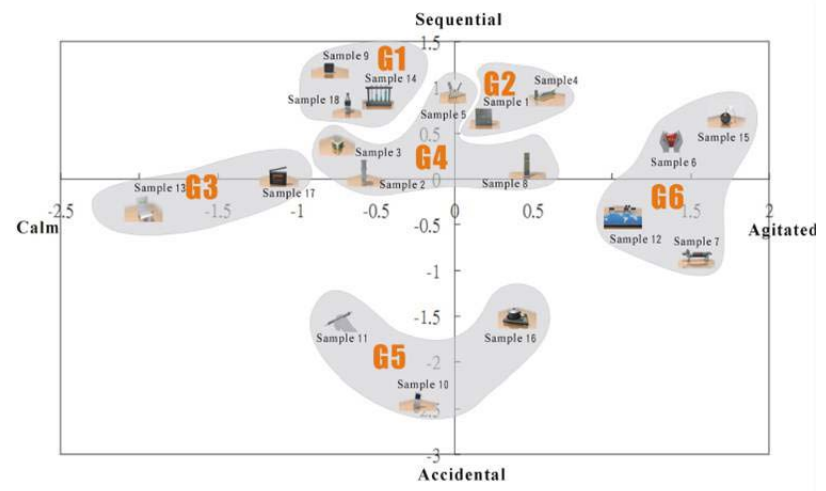

Figure 5: Image map plotted by using the first ( $\mathrm{X}$ axis) and the third ( $\mathrm{Y}$ axis) principle component.

group includes sample 1, 4, and the overall tendency was "agitated, transparent, and sequential". The feature of this group could be explained as "unfamiliar appearance, careful operation, and surprising result". G3 group includes sample 13,17, and the overall tendency was "calm, transparent". The feature of this group could be explained as "known appearance, continuous operation, and indirect result". G4 group includes sample 2, 3, 5, 8, and the overall tendency was "ambiguous". The feature of this group could be explained as "unknown appearance, changeable operation and ambiguous, result". G5 group includes sample 10,11,16, and the overall tendency was "accidental". The feature of this group could be explained as "definite appearance, familiar operation and accidental result”. G6 group includes sample 6, 7, 12, 15, and the overall tendency was "agitated, transparent". The feature of this group could be explained as "associated appearance, simple operation and clear result".

\subsection{Tendency of 6 Sample Groups}

In addition, a broken line graph was used to understand the changes of principle component and overall evaluation during the 3 different stages, as shown in Table 5 and 6.
Table 5: Changes of expected image principal components of 6 sample groups in different stages

\begin{tabular}{|l|l|l|l|}
\hline & \multicolumn{2}{|c|}{ Description } \\
\hline & & & \\
\hline
\end{tabular}

Table 6: Changes of comprehensive evaluation of 6 sample groups in different stages

\begin{tabular}{|l|l|l|l|}
\hline & \multicolumn{1}{|c|}{ Description } \\
\hline & \multicolumn{2}{|c|}{ Broken line graph } & $\begin{array}{l}\text { In development stage, most of } \\
\text { sample groups have the } \\
\text { tendency to higher "expecting" } \\
\text { feeling and lower in ending } \\
\text { stage. } \\
\text { Only the accidental result of } \\
\text { G5 keeps the continues rising } \\
\text { tendency. }\end{array}$ \\
\hline
\end{tabular}




\subsection{Overall Evaluations}

According to the overall evaluation scores, it was found that G6 (associated appearance, simple operation and clear result) has the highest scores in "Expecting" (5.35), "Interesting" (5.41), and "Favorable" (5.20) evaluation, as shown in Figure 6.

\subsection{Design Techniques in Different Stages}

Among the design techniques in the product-use starting stage, "the Appearance is different from the existing features" tends to cause people to have "expecting, surprising, eager, unknown, ambiguous, expecting and

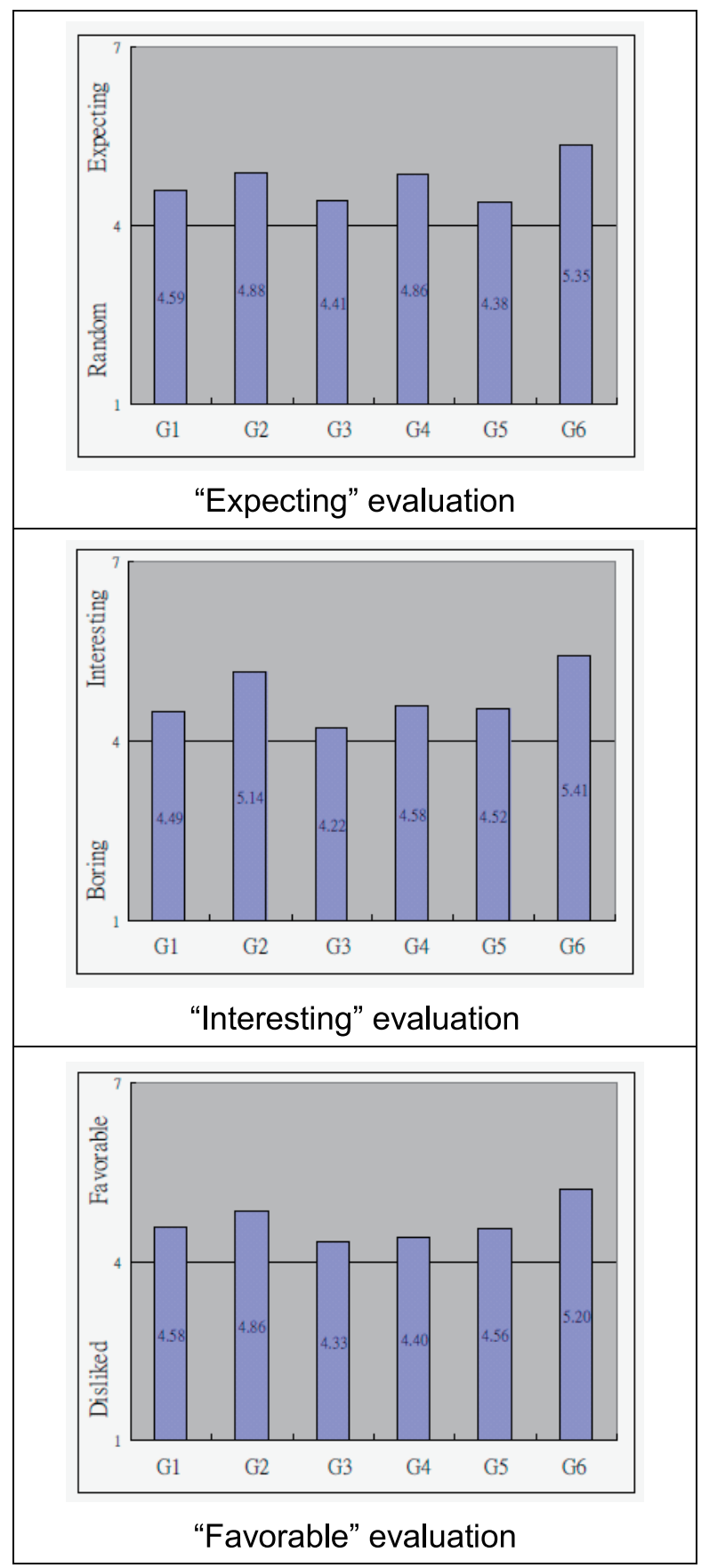

Figure 6: Comparison of overall evaluation of 6 sample groups interesting" feelings. Most of the evaluations tend to be high in starting and development stages and low in ending stage. "Appearance implies purposes" tends to make people to have "ordinary, old-fashioned, known, dull, fixed and clear" feelings. The evaluations tend to be low in starting and development stages and high in ending stage. (Figure 7)

Among the design techniques in the product-use development stage, "Implying the suspended result" tends to make people to have "expecting, surprising, eager, sequential, clear, fixed, expecting, interesting and favorable" feelings. "Back-and-forth operating method" makes people to have "creative, unknown, changeable and passionate" feelings. The evaluation of "Careful operation process" is insignificant in development stage and rises in ending stage. (Figure 8)

Among the design techniques in the product-use ending stage, "Presenting the unforeseen result" tends to make people to have "surprising, creative, unknown, exciting, changeable, accidental, passionate, interesting and favorable" feelings. In addition, the evaluations in starting and development stages tend to be low and they become high in ending stage. "Ambiguous result presenting" tends to make people to have "unknown, dull and expecting" feelings. "Strengthening result presenting" tends to make people to have "expecting, known, fixed and clear" feelings in ending stage. (Figure 9)

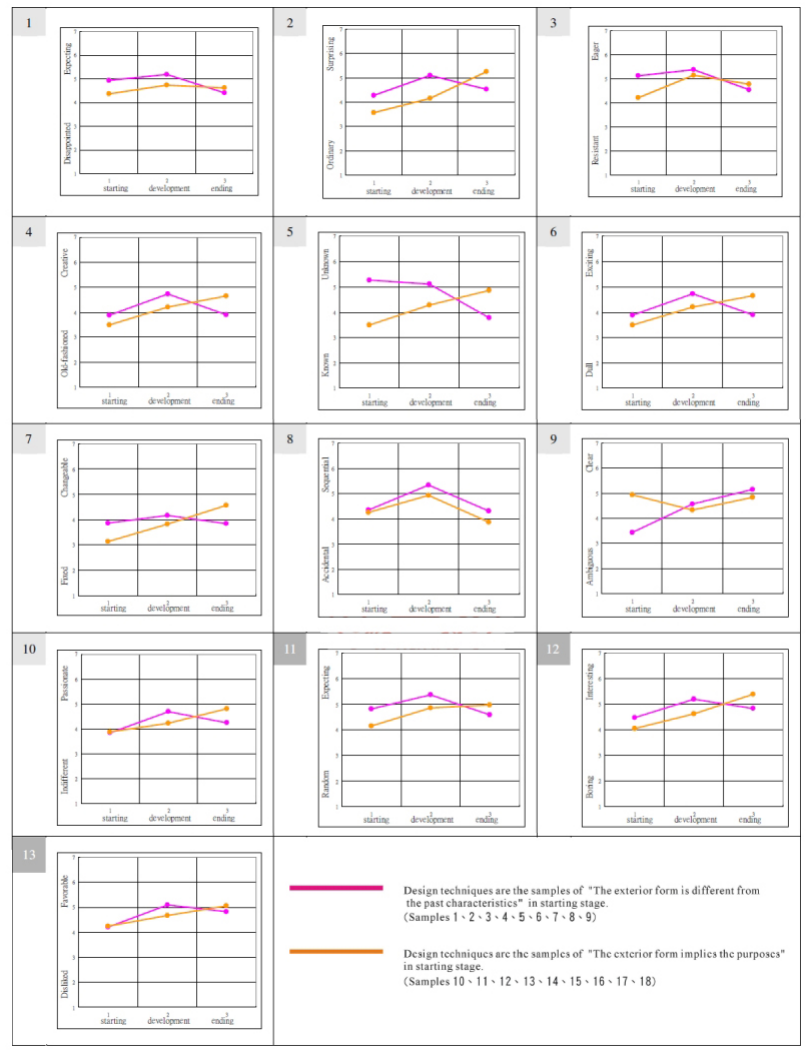

Figure 7: Changes of design techniques in starting stage, expected image and the overall evaluation in different stages. 


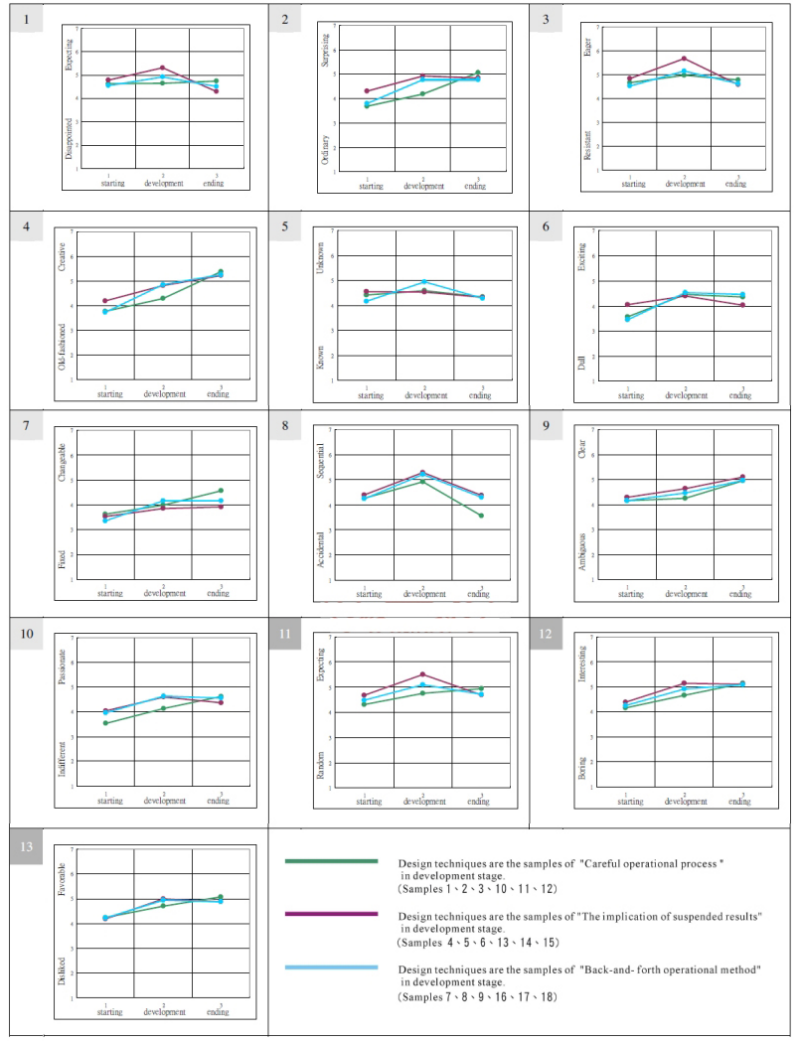

Figure 8: Changes of design techniques in development stage, expected image and comprehensive evaluation in different stages.

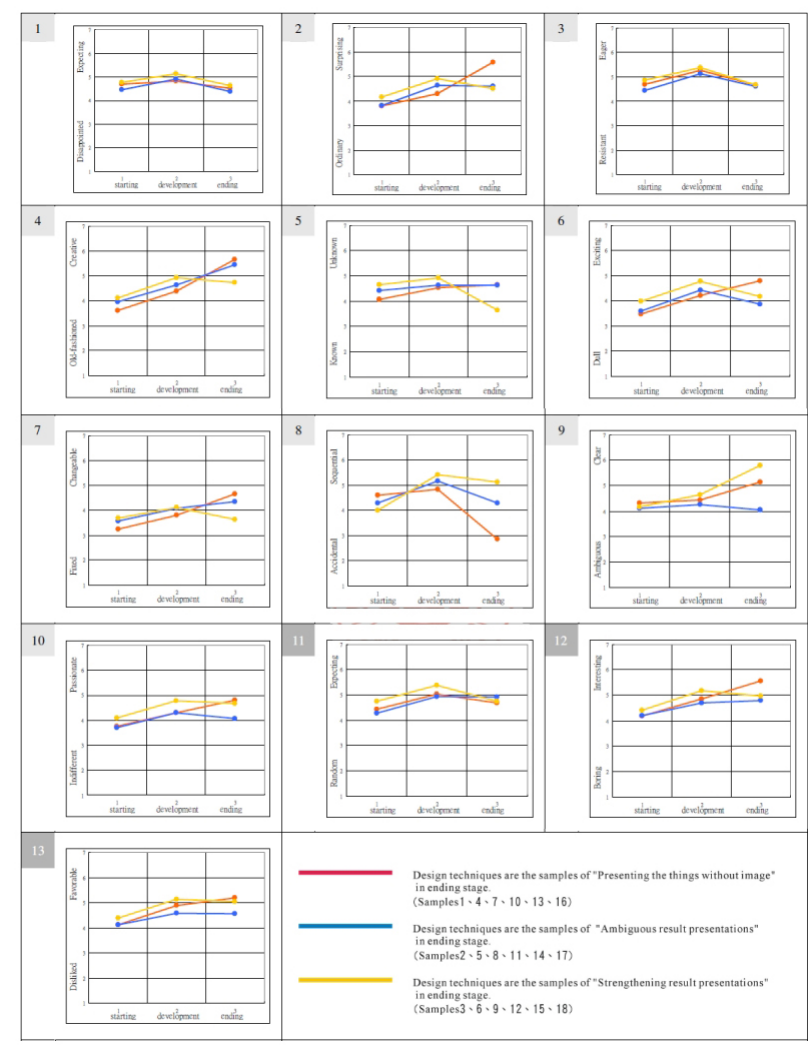

Figure 9: Changes of design techniques in ending stage, expected image and comprehensive evaluation in different stages

\subsection{Comparison of Design Techniques}

The comparison of design techniques can be summarized as Table 7.

\section{CONCLUSION}

The expected image for using products consists of 3 aspects: "agitated -- calm" aspect showing the emotional change levels, "ambiguous -- transparent" aspect for delivering the users definite messages and "sequential -accidental" aspect for predicting the next step.

In expected image, "agitated" feeling is insignificant at the beginning and it slightly rises in development stage and slightly declines in ending stage. However, when

Table 7: Comparison of design techniques in different stages and the influence on the whole process

\begin{tabular}{|c|c|c|c|}
\hline $\begin{array}{c}\text { Product- } \\
\text { use } \\
\text { Stages }\end{array}$ & $\begin{array}{c}\text { Design } \\
\text { Techniques }\end{array}$ & $\begin{array}{l}\text { Possible images } \\
\text { from the design } \\
\text { techniques }\end{array}$ & $\begin{array}{c}\text { Influences to the } \\
\text { whole process }\end{array}$ \\
\hline \multirow{2}{*}{$\begin{array}{l}\text { Starting } \\
\text { stage }\end{array}$} & \begin{tabular}{|l|} 
the Appearance is \\
different from the \\
existing features
\end{tabular} & $\begin{array}{l}\text { Expecting, } \\
\text { surprising, eager, } \\
\text { unknown, } \\
\text { ambiguous, } \\
\text { expecting, } \\
\text { interesting }\end{array}$ & $\begin{array}{l}\text { The evaluation is } \\
\text { high in starting } \\
\text { and development } \\
\text { stages and low in } \\
\text { ending stage. }\end{array}$ \\
\hline & $\begin{array}{l}\text { The appearance } \\
\text { implies the } \\
\text { purposes }\end{array}$ & $\begin{array}{l}\text { Ordinary, } \\
\text { old-fashioned, } \\
\text { known, dull, fixed } \\
\text { and clear }\end{array}$ & $\begin{array}{l}\text { The evaluation is } \\
\text { low in starting } \\
\text { and development } \\
\text { stages and high in } \\
\text { ending stage. }\end{array}$ \\
\hline \multirow{3}{*}{$\begin{array}{l}\text { Develop- } \\
\text { ment } \\
\text { stage }\end{array}$} & $\begin{array}{l}\text { Carefully } \\
\text { operating } \\
\text { process }\end{array}$ & $\begin{array}{l}\text { No significant } \\
\text { feelings }\end{array}$ & $\begin{array}{l}\text { It is lower in } \\
\text { development } \\
\text { stage; however, } \\
\text { the rising tendency } \\
\text { continue to ending } \\
\text { stage and becomes } \\
\text { the highest in } \\
\text { ending stage. }\end{array}$ \\
\hline & \begin{tabular}{|l|} 
Implying the \\
suspended results
\end{tabular} & $\begin{array}{l}\text { Expecting, } \\
\text { surprising, eager, } \\
\text { sequential, clear, } \\
\text { fixed, expecting, } \\
\text { interesting, } \\
\text { favorable }\end{array}$ & $\begin{array}{l}\text { No significant } \\
\text { influence in other } \\
\text { stages; however, } \\
\text { the evaluation in } \\
\text { development stage } \\
\text { tends to be high. }\end{array}$ \\
\hline & $\begin{array}{l}\text { Back-and-forth } \\
\text { operating method }\end{array}$ & $\begin{array}{l}\text { Creative, unknown, } \\
\text { changeable, } \\
\text { passionate }\end{array}$ & $\begin{array}{l}\text { No significant } \\
\text { influence on other } \\
\text { stages }\end{array}$ \\
\hline \multirow{3}{*}{$\begin{array}{l}\text { Ending } \\
\text { stage }\end{array}$} & \begin{tabular}{|l|} 
Presenting the \\
unforeseen results
\end{tabular} & $\begin{array}{l}\text { Surprising, creative, } \\
\text { unknown, exciting, } \\
\text { changeable, } \\
\text { accidental, } \\
\text { passionate, } \\
\text { interesting, } \\
\text { favorable }\end{array}$ & $\begin{array}{l}\text { The evaluation is } \\
\text { lower in starting } \\
\text { and development } \\
\text { stages, but the } \\
\text { highest in ending } \\
\text { stage. }\end{array}$ \\
\hline & \begin{tabular}{|l|} 
Ambiguous result \\
presenting
\end{tabular} & $\begin{array}{l}\text { Unknown, dull, } \\
\text { expecting }\end{array}$ & $\begin{array}{l}\text { "Creative and } \\
\text { changeable" } \\
\text { feelings still } \\
\text { increase in } \\
\text { ending stage }\end{array}$ \\
\hline & $\begin{array}{l}\text { Strengthening } \\
\text { result presenting }\end{array}$ & $\begin{array}{l}\text { Expecting, known, } \\
\text { fixed, clear }\end{array}$ & $\begin{array}{l}\text { "Clear" feeling } \\
\text { still increases in } \\
\text { ending stage }\end{array}$ \\
\hline
\end{tabular}


indirect or accidental results show in ending stage, agitated feeling will still continue rising. In addition, with the gradually better understanding to the products, "transparent" feeling will rise. However, accidental result in clear appearance and familiar operation will make people feel "ambiguous". "Sequential" feeling is insignificant in starting stage and it significantly increases in development stage when people start using the products. It will decline in ending stage. When accidental, indirect or accidental result appears, "accidental" feeling will considerably rise.

"Expecting" feeling usually slightly rises in development stage and declines in ending stage after the answers reveal. If it is accidental result, it will rise in ending stage. "Interesting" feeling slightly rises in development stage and remains the same in ending stage. However, ambiguous result in ending stage will reduce interesting feeling; accidental result will considerably increase interesting feeling. "Favorable" feeling is insignificant in starting stage without using the product, it slightly rises in development stage and declines in ending stage. Accidental result will make it to continue rising in ending stage. In terms of the evaluation of the whole process, "associated appearance, simple operation and clear result" show the highest comprehensive evaluation in different aspects and people tend to have "expecting", "interesting" and "favorable" feelings.

With regard to the comparisons among design techniques in different stages and the influence on the whole process, in the design techniques in starting stage, "the Appearance is different from the existing features" tends to make people to have "expecting, surprising, eager, unknown, ambiguous, expecting and interesting" feelings. Most of the evaluations tend to be high in starting and development stages and low in ending stage. "Appearance implies purposes" tends to make people to have "ordinary, old-fashioned, known, dull, fixed and clear" feelings. The evaluations tend to be low in starting and development stages and high in ending stage.

In design techniques in development stage, "implying the suspended result" tends to make people to have "expecting, surprising, eager, sequential, clear, fixed, expecting, interesting and favorable" feelings. "Backand-forth operating method" makes people to have "creative, unknown, changeable and passionate" feelings. The evaluation of "careful operation process" is insignificant in development stage and rises in ending stage.
In design techniques in ending stage, "presenting the unforeseen results" tends to make people to have "surprising, creative, unknown, exciting, changeable, accidental, passionate, interesting and favorable" feelings. In addition, the evaluations in starting and development stages tend to be low and they become high in ending stage. "Ambiguous result presenting" tends to make people to have "unknown, dull and expecting" feelings. "Strengthening result presenting" tends to make people to have "expecting, known, fixed and clear" feelings in ending stage.

\section{ACKNOWLEDGEMENTS}

Financial support of this research by National Science Council, Taiwan, R.O.C. under the grant of General Research Project NSC100-2221-E-036-038 is gratefully acknowledgement.

\section{REFERENCES}

1. Donald, A. Norman; Emotional design: why we love (or hate) everyday things (Chinese version), Garden City Publishing Ltd, Taipei, Taiwan, (2005).

2. Chang, C.H; Psychology (in Chinese), Tong hua book store, Taipei, Taiwan, (1988).

3. Edward S. Reed, Michael Montgomery, Carolyn Palmer and John Pittenge; Method for studying the invariant knowledge structure of action: conceptual organization of an everyday Action, The American Journal of Psychology, 108, pp.37-65 (1995).

4. Tsao, Y.C., Hsiung, C.C.; Relationship between the adverbial images of complex actions in using utensils and the forms of the utensils, In Proc. the 5th Annual International Conference on Industrial Engineering Theory, Applications and Practice, pp.577-582 (2000).

5. Chou, C.H.; Story (in Chinese), Wunan press, Taipei, Taiwan, (2002).

6. Tsao, Y. C., Chen, Brian, and Yang, Y.P.; A Study on the Expected Image and Relevant Design Techniques in Different Product-Use Stages, In Proc. HCI 2011, pp.655-663 (2011).

7. Tsao, Y. C., Chen, S. Y. (2007). The expected image in the process of using products. In Proc. KEER 2007. 


\section{Appendix}

The 18 test samples.

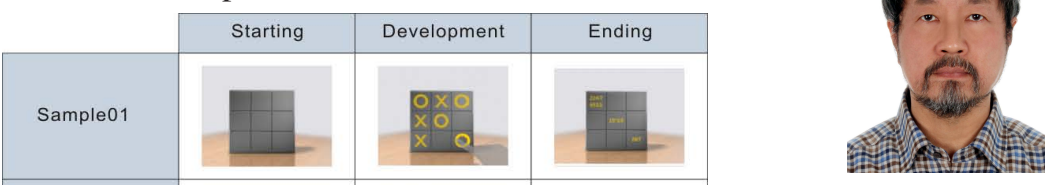

\section{Yung-chin TSAO}

Mr. Yung-chin Tsao is an associate professor of College of Design, Tatung University. He has been the chair of Industrial Design department and also the director of the graduate institute of Tatung University during 1998-2004 and 2007-2010. He is now the director of the Graduate Institute of Design Science, College of Design, Tatung University. He is engaged in Product Design, Design Image, Design Method, Kansei Engineering, and Universal Design etc. Currently, his recent research interests are: (1) the design model for constructing the relationship between expectation image of product operation and time element; (2) the application of Universal Design on Transportation Environment. (tsao@ttu.edu.tw)

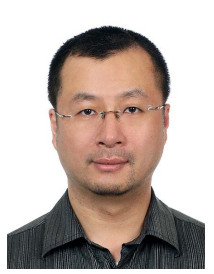

\section{Pochuan CHEN}

Pochuan Chen is a student on his phd study, at Graduate Institute of Design Science of Tatung University since 2009. He has more than 15 year working experiences on Computer-Aided Industrial Design and Industrial design projects, since he was graduated from Industrial Design Department and Mechanical Engineering Graduate School of Tatung University. The product types he experienced were including smart-phone, laptop pc, industrial computer, ebook reader, medical device and so on. Currently, his research interests are Kansei Engineering, Human-product interaction, and Design model. Especially using behavior unitization to study product use process. He is now also the design director of Gigatech R\&D Ltd., Taipei, Taiwan.

(bchen1969@gmail.com)

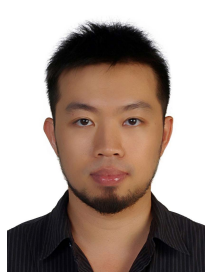

\section{Yen-pang YANG}

Yen-pang Yang has studied architecture and industrial design when he was at school. And he has the experiences on studying Kansei Engineering and Product Image, under the instruction of professor Yung-chin Tsao at Graduate School of Industrial Design, Tatung University. During his school career, he has the following achievements: publishing two conference papers, involving in two industry-school cooperated projects, and get twice Honorable Mention on Product Design Competition. After he graduated from school, he was working at Kuzai Art Studio for project planning of Public Art and also executing related design tasks.

(F1200@ms38.hinet.net) 